\title{
Extended criteria donors in liver transplantation Part I: reviewing the impact of determining factors
}

\section{Balázs Nemes, György Gámán, Wojciech G. Polak, Fanni Gelley, Takanobu Hara, Shinichiro Ono, Zhassulan Baimakhanov, Laszlo Piros \& Susumu Eguchi}

To cite this article: Balázs Nemes, György Gámán, Wojciech G. Polak, Fanni Gelley, Takanobu Hara, Shinichiro Ono, Zhassulan Baimakhanov, Laszlo Piros \& Susumu Eguchi (2016): Extended criteria donors in liver transplantation Part I: reviewing the impact of determining factors, Expert Review of Gastroenterology \& Hepatology

To link to this article: http://dx.doi.org/10.1586/17474124.2016.1149061

Accepted author version posted online: 03 Feb 2016.

Submit your article to this journal

ai

View related articles $₫$

View Crossmark data \ulcorner 
Publisher: Taylor \& Francis

Journal: Expert Review of Gastroenterology \& Hepatology

DOI: $10.1586 / 17474124.2016 .1149061$

Extended criteria donors in liver transplantation Part I: reviewing the impact of determining factors

\author{
Balázs Nemes ${ }^{1}$ \\ György Gámán ${ }^{2}$ \\ Wojciech G. Polak ${ }^{3}$ \\ Fanni Gelley ${ }^{4}$ \\ Takanobu Hara ${ }^{5}$ \\ Shinichiro Ono ${ }^{5}$ \\ Zhassulan Baimakhanov ${ }^{5}$ \\ Laszlo Piros ${ }^{2}$ \\ Susumu Eguchi ${ }^{5}$
}

1. Department of Organ Transplantation, Faculty of Medicine, Institute of Surgery, University of Debrecen. Hungary

2. Clinic of Transplantation and Surgery, Semmelweis University, Budapest, Hungary

3. Department of Surgery, Division of Hepatopancreatobiliary and Transplant Surgery, Erasmus MC, University Medical Center Rotterdam, Rotterdam, The Netherlands

4. Dept of Internal medicine and Gastroenterology, Polyclinic of Hospitallers Brothers of St. John of God, Budapest, Hungary

5. Department of Surgery, Nagasaki University Graduate School of Biomedical Sciences, Japan

\title{
Corresponding author:
}

\section{Balazs Nemes}

Department of Organ Transplantation, Faculty of Medicine, Institute of Surgery, University of Debrecen, Hungary

Postal address: Moricz Zs. krt 22. H-4032, Debrecen, Hungary; Telefax : +36-52-255-544

Cellphone: +36-30-983-4764

Email: abnemes@hotmail.com 


\section{Abstract}

The definition and factors of extended criteria donors have already been set, however details of the various opinions still differ in many respects. In this review, we summarize the impact of these factors and their clinical relevance. Elderly livers must not be allocated for hepatitis $\mathrm{C}$ virus (HCV) positives, or patients with acute liver failure. In cases of markedly increased serum transaminases, donor hemodynamics is an essential consideration. A prolonged hypotension of the donor does not always lead to an increase in post-transplantation graft loss if postOLT care is proper. Hypernatremia of less than $160 \mathrm{mEq} / \mathrm{L}$ is not an absolute contraindication to accept a liver graft per se. The presence of steatosis is an independent and determinant risk factor for the outcome. The gold standard of the diagnosis is the biopsy. This is recommended in all doubtful cases. The use of $\mathrm{HCV}+$ grafts for $\mathrm{HCV}+$ recipients is comparable in outcome. The leading risk factor for HCV recurrence is the actual RNA positivity of the donor. The presence of a proper anti-HBs level seems to protect from de novo HBV infection. A fayourable outcome can be expected if a donation after cardiac death liver is transplanted in a favourable condition, meaning, a warm ischemia time $<30$ minutes, cold ischemia time $<8-10$ hours, and donor age 50-60 years. The pathway of organ quality assessment is to obtain the most relevant information (e.g. biopsy), consider the co-existing donor risk factors and the reserve capacity of the recipient, and avoid further technical issues.

\section{I) Introduction}

The use of extended criteria donors (ECD) became an acceptable compromise in liver transplantation (OLT). Unnecessary refusal of potential donor livers was reported more than a decade ago [1]. How should the advantages and disadvantages of extended criteria donors be measured? Is waitlist mortality (WLM), versus the cumulative, patient and graft survival a the measurable cornerstone? Are the definitions of ECD homogenous? We reviewed the literature surrounding this topic. The main issues were to focus on the main parameters, like graft steatosis, donor age, hepatitis $C$ virus, and hepatitis B virus positive grafts, as well as DCDs. No unique parameter exists that is relevant to assess the quality of a donor liver. The factors can be divided into donor parameters, logistical parameters, and recipient factors. In order to assess the EC, the donor age, and liver function tests, are the first, basic filters, which will be followed by the donor management parameters, like ventilation time, the amount of catecholamines, circulatory instability, and temporary cardiac arrest. The assessment of steatosis is useful, and important, but the feasibility of a mandatory biopsy is questionable. Organ shortage provoked to accept $\mathrm{HBV} / \mathrm{HCV}$ positive, and CDC donor livers. We discuss the experience about these factors in the 
relevant literature. The outcome parameters and survival results are discussed in the second chapter of the review.

\section{II) Background}

Definition, categorization, and factors of extended criteria donors were already set in 2007 by Barshes, Nickkholgh, the Heidelberg group, Northup, and others[2,3,4]. The composites of these definitions are summarized on Table 1. Other studies revealed on a similar criterion like Schemmer et al [5], and Afonso et al [6]. Finally the Paris-consensus meeting with the contribution of experts from Europe, the United States, and Asia declared that donor quality represents a continuum of risk rather than "good or bad", declaring that using an ECD is needed, even if it generates increased morbidity and mortality [7]. An ideal donor is different from an ideal graft, because CIT, or technical variants, such as split-liver allograft might also have an influence. After the publication of the Paris-consensus meeting, the ECD definition was mainly confined to the direct donor factors to assess the risk at the time of procurement. The Donor Risk Index (DRI) was established by Feng $S$ to help assess the risk for a given donor [8], however it does not take steatosis intoaccount, but the donor's age, race, height, and COD; the split liver donation status; the DCD status; the type of allocation (local, regional, or national); and the CIT are included. This is also seen in Table 1, that the approach to ECD has moved from age, to allocation, and steatosis. Among European or Asian populations, some variables such as African-American or regional sharing versus national sharing are not relevant [7]. The quality of a donor liver has a strong correlation with the incidence of the early allograft dysfunction (EAD), or initial poor function (IPF). Definition varies, can be established by the recovery of hepatocytes [9] as ALAT and/or ASAT above 1500 IU/L within 72 hours after OLT. Also detoxication, and synthetic function can be measured [10] when IPF is declared if the quotient of spontaneous prothrombin (PT) time and serum bilirubin is $<1$ on the day 5 th after OLT. Lucidi $V$ et al [11] combine the two: Others declare IPF as good, fair, or poor function according to the ASAT and PT over the first 5 days [12]. Müllhaupt et al divided risk factors as donor, and transplant ones. Donor nonCaucasian race, and CVA (as COD) are given, while donor BMI, and diabetes were found not be significant risk factors [13]. Feng et al evaluated the data of 20000 donors in 2006: age, race, donor height, CVA (as COD), and partial/split graft independently increased the risk for graft failure. Donors with a prolonged ICU management ( $>7$ days), cardiopulmonary resuscitation, and use of inotropes rescued for an infection [8].

Others did not find adverse outcomes if the recipient received a graft from an infected donor [14]. With respect to grafts from donors with central nervous system malignancy (CNS) it was 
reported that in 179 cases of liver grafts from CNS donors, only $1(0,55 \%)$ transmission was observed to the recipient. These donors can be used in fully informed patients who have a high risk of death without an OLT [15].

Burroughs et al revised the overall UCLA experience (10000 allografts) in 2009. Significant factors with multivariate analysis were; donor hospital stay $>5$ days, donor age $>55$ years old, CIT $>12 \mathrm{~h}$, and WIT $>40 \mathrm{~min}$ [16]. Results of the University of Montreal concluded on 634 grafts to 634 recipients $(52,8 \%$ had at least $1 \mathrm{ECD}$ score), that factors associated with graft survival were the graft gross appearance $(\mathrm{P}<0.001)$, the donor partial pressure of oxygen/fraction of inspired oxygen ratio (less than $300 \mathrm{~mm} \mathrm{Hg}$ ), and the donor haemoglobin level (higher than $100 \mathrm{~g} / \mathrm{L}$;). $[17]$.

Factors for a graft failure were divided into those for the recipient (HCV positivity, any diagnosis with malignancy, previous OLT, a BMI >30) and those for the donor (anti-HBc positivity, arterial pressure $<60 \mathrm{~mm} \mathrm{Hg}$ for $>20$ min., and CIT $>6$ hours). The 5-years graft survival was $83 \%$ in the low risk (ECD 0-1) group vs 62\% in the intermediate (ECD 2-4), and $0 \%$ high risk (ECD >4) group [18]. A recent large study by European Liver Intestine Transplant Association (ELITA) and Eurotransplant Liver Intestine Advisory Committee (ELIAC) reports more than 50\% incidence of ECDs in ET in 2012 [19]. They enrolled all 6621 OLTs performed within ET, and validated the DRI developed by OPTN, for the ET as well. The following criteria are being used as risk factors within the ET group: a donor age > 65 years; ICU stay > 7 days; high BMI; steatosis; hypernatremia; high levels of ASAT, ALAT, and serum bilirubin. Among all donors, transplants and recipient variables used in the ET, finally the DRI was the strongest predictor of the outcomes [19]. A yery similar approach, within the framework of European Liver Transplant Registry (ELTR) was published: in the multivariate analysis of 4701 donor's data, CIT, highest sodium, COD, gamma glutamyl transferase $(\gamma \mathrm{GT})$, and donor sex (female) were statistically significant factors for 3 months, and CIT, $\gamma \mathrm{GT}$, and COD for 12-month survival. The median DRI of this study population was 1.45 [20].

The results of the ELITA-ELTR questionnaire about ECD definitions of 35 OLT centres are: steatosis in $94 \%$ of centres; age up to 80 years (43\%); serum sodium $>165 \mathrm{mmol} / \mathrm{L}(71 \%)$; ICU stay with ventilation $>7$ days (48\%); ASAT >90 U/L, (17\%); BMI >30 in 54\%); ALAT >105 $\mathrm{U} / \mathrm{L}(23 \%)$; serum bilirubin $>3 \mathrm{mg} / \mathrm{dL}(43 \%)$; and all criteria together in 2 centres $(6 \%)$ [21]. Arjona-Sanchez et al suggested a prediction model to discard á priori liver grafts by three variables: age, pathological ultrasonography, and BMI $>30$. The area under curve was $82.7 \%$, and for a probability to discard of $70 \%$, the false-positive probability was $1.2 \%$ [22]. 
In conclusion when talking about ECD, we should mention donor age, abnormal liver function tests, hypernatremia, steatosis of the donor liver, prolonged ICU stay, the use of vasopressors, resuscitation and donors with $\mathrm{HCV} / \mathrm{HBV}$ positivity as a minimal consensus that has not changed since 2007. It has been demonstrated that DCD or non-heart beating donors (NHBD), and macrosteatosis of the graft liver must be considered as separate risk factors, inducing graft dysfunction and increased injury post-LT. Macrovesicular steatosis is characterized by a single fat vacuole larger that nucleus, which displaces the nucleus to the periphery. Its grade correlates with the incidence and severity of graft dysfunction. It is debatable to define split (reduced size) liver grafts as ECD or not. In summary, the elements of discussion are the conventional and nonconventional risk factors of ECD.

\section{III) Conventional factors of an Extended Criteria Donor}

This chapter briefly discusses conventional" ECD parameters. These are the donor age, abnormal liver function tests, circulatory instability in a brain death donor (or temporary cardiac arrest), alcohol abuse, infection of the donor, hypernatremia and liver steatosis. We call them conventional since they were involved in the assessment of all (also non-ECD) donors from the beginning.

\section{1) Donor age}

The age is a relevant factor [23,24], that has steadily increased: in 1994 only $20 \%$ of donors were 50 years or older, and it has doubled till today in the US [13]. The annual number of donors aged $>65$ years has been increased 14-fold between 1991 to 2001 in the UNOS database, and the rate of donors $>60$ years increased from $2 \%$ to $20 \%$ in the ELTR [3]. Routine liver function tests do not show age-associated changes, hepatic flow decreases about $35 \%-40 \%$ and bile flow about $50 \%$, reflecting at least in part, impairment of energy-dependent and microtubule-dependent transport processes. The cytochrome P450 content of liver specimens is recently reported to decline from the age of 40 to 69 years by $16 \%$ and further decline by $32 \%$ over age of 70 .

However this paradigm shift has not negatively impacted graft or patient survival [23]. The Paris consensus meeting reported that there is no absolute limit of donor age for liver transplantation, however it is strongly recommended not to allocate elderly donors to HCV-infected recipients [7], since a donor age between 61-70 gives a relative risk 1,53 (Odds Ratio) for HCV recurrence, while it is 1.65 over 70 years of age [13]. Others did not confirmed donor gender as a risk factor [13], and successful utilization of liver graft from donors older than 80 years of age are published [24]. In contrast Serrano et al reported an increased risk of non-anastomotic biliary stricture in case 
of donors $>60$ years of age [25], which is in accordance with a recent nationwide German multicentre study [26]. Kim DY et al identified recipient HCV positivity, model for end stage liver disease $($ MELD) $>20$, donor serum glucose $>200 \mathrm{mg} / \mathrm{dL}$, and more than 40 minutes to aortic crossclamp in donor surgery, as risk factors in addition to donor age $>65$ years. The 5 years graft survival rates, having $0,1,2,3$, and 4 unfavourable characteristics were $100 \%, 82.0 \%, 81.7 \%$, $39.3 \%$, and $25.0 \%$, respectively $(\mathrm{p}<0.05)$. A good graft survival can be achieved using elderly donor liver allografts with appropriate recipient selection, donor blood glucose management and efficient liver recovery with minimal manipulation of the liver during donor surgery [27]. An additive risk factor is the transmission of malignancies since the high incidence of unrecognized malignancies in the elderly [28]. In a recent retrospective, single centre study $10 \%$ of recipient had a liver from a donor older than 80 years. There was no difference in terms of early $(\leq 30$ days $)$ graft loss but, the 5-year graft survival was lower for HCV-positive versus HCV-negative recipients $(62.4 \%$ vs. 85.6$)$ in the group $\geq 80$ years [29]. In conclusion we can say that the age of reported donors increases with time. Age should not be considered as an independent risk factor, only if that occurs in parallel with some others. An elderly liver must not be allocated for HCV positive recipients, or patients with an acute liver failure, but they can be used safely for other indications

\section{2) Abnormal liver function tests}

There is no clear upper limit in serum transaminases that is a contraindication. [13]. The elevated LFTs are not specific. They represent a certain problem, but do not give a key to the problem itself: that can be HCV infection, ischemia injury, steatosis, temporary circulatory arrest etc. Also a, normal or near normal liver function test is not a guarantee that there are no significant parenchymal lesions. In cases of markedly increased serum transaminases, donor hemodynamics is an essential consideration. During the Paris consensus meeting in 2008, it was also agreed that in the case of a marked increase in the $\gamma$ GT level, and/or an increased international normalized ratio(INR), the other donor factors, including a history of alcohol abuse and non-alcoholic steatohepatitis (NASH), should be carefully assessed before procurement is considered, and .a liver biopsy is warranted. [7]. Donor livers with a median ASAT $1400 \mathrm{U} / \mathrm{L}$, ALAT 1026 U/1. were accepted for OLT, showing a peak in transaminases on the day of surgery, but normalized in one week [30].

\section{3) Circulatory instability}


Lucidi et al reported their risk factors as high vasopressor use, ICU stay $>4$ days and BMI $>30$, that were present in respectively $44 \%, 27 \%$, and $16 \%$ of the donors. They failed to observe significant differences in initial graft function. Bad initial function (IPF + primary non function $(\mathrm{PNF})$ ), was in most cases associated with donor peak serum $\mathrm{Na}+>160 \mathrm{mEq} / \mathrm{L}$ and ICU stay $>$ 4 days (Odds ratios of 26.9 and 4.4, respectively). [11]. It is suggested that prolonged hypotension of the donor during ICU management have no significant increase in post-transplantation graft loss. However, graft loss was increased in liver transplant recipients, when donors received norepinephrine together with dopamine (dose $>10 \mu \mathrm{g} / \mathrm{kg} / \mathrm{min}$ ) [28]. Temporary cardiac arrest might occur in any donor. Hoyer et al identified 77 donors with temporary cardiac arrest of 884 OLTs after DBD. In the patient group with cardiac arrest, the median resuscitation time was 16.5 minutes. There was no difference in patients and graft survival between the two groups. Multivariable analysis identified CIT as a risk factor for both patientand graft survival in these donors [31].

\section{4) Alcohol abuse, and infection}

Wu et al. [14] reported that in case of grafts from a donor with a positive culture there was no significant increase in adverse outcomes of the recipient. Mangus et al divided donors with a documented history of alcohol consumption into three groups according to duration of abuse ( $<10$ years, $10-24$ years and $>25$ years). Of the revised 1478 consecutive donors only $11 \%$ had alcohol abuse at all. Risk of 90-day graft loss for the three groups was: $0 \%, 3 \%$ and $2 \%$, compared to $3 \%$ for all other donors $(P=0.62)$. Also there was no statistically significant difference up to 10 years post-transplant [32].

\section{5) Hypernatremia}

Hypernatremia is a common complication in brain death patients. Several reports have suggested donor hypernatremia to have negative effects on graft dysfunction and mortality [33-35]. There are reports about direct correlation between the serum sodium level of the donor and the posttransplantation transaminase levels of the recipients, and EAD, as well as higher level of postoperative serum bilirubin $[37,38,39]$. Figueras et al. also noted that a donor plasma sodium level of $>155 \mathrm{mmol} / \mathrm{L}$ was associated with higher rates of liver retransplantation and graft loss within 1 month after transplantation which would reflect severe cellular damage [35]. This is an accordance with the report of Totsuka et al. who found prolonged coagulation times, associated with poor graft outcomes [36,37]. In contrast, the correction of the donor serum sodium level to less than $155 \mathrm{mEq} / \mathrm{L}$ before organ procurement resulted in improved hepatic allograft survival 
and function. Although the mechanism was not elucidated, the author considered that the primary cause of hepatocyte death and graft dysfunction was increased hepatocellular osmolality. Powner et al. suggested that extracellular water is translocated into the hepatocytes where it leads to increased intracellular osmolality and causes cellular swelling [38].

Conversely, recent studies have found there to be no correlation between donor hypernatremia and graft function or loss. Tector et al. found that donor peak serum sodium $>170 \mathrm{mEq} / \mathrm{L}$ was not associated with graft loss or dysfunction [39]. Renz et al. who defined hypernatremia as a serum sodium level of $>155 \mathrm{mEq} / \mathrm{L}$ also found that hypernatremia did not influence graft survival [40]. Akoad et al. reported that the rate of PNF, early graft failure within 30 days and 1year patient and graft survival of recipients from donors with hypernatremia $(>160 \mathrm{mEq} / \mathrm{L})$ were similar those in recipients of grafts from donors with optimal sodium levels [41]. Cyminski et al. also showed that donor serum sodium levels of $>155 \mathrm{mEq} / \mathrm{L}$ did not affect the liver function tests (ASAT, ALAT, and total bilirubin), the length of ICU stay, and the length of hospital stay, early recipient survival or early graft function [42]. Mangus et al. found that severe donor hypernatremia (> $170 \mathrm{mEq} / \mathrm{L}$ ) had a minor clinical impact on the ALAT level on post-transplant day 1 , but no impact on early liver function or risk of failure, for up to 1-year after transplantation [43]. Goldaracena et al. reported that there was no significant difference in the 30day and 1-year mortality rates of the recipients of extremely marginal liver grafts from with a serum sodium concentration of $>155 \mathrm{mEq} / \mathrm{L}$ and the recipients of optimal-state grafts [44]. Khosravi et al. compared the ASAT, ALAT, INR, and kidney function at post-transplant day 5 in recipients from donors with terminal donor serum sodium concentration of $155 \mathrm{mEq} / \mathrm{L}$ or greater and recipients from donors with a terminal donor serum sodium concentration of less than $155 \mathrm{mEq} / \mathrm{L}$ and found no difference between the two groups of recipients [45]. In pediatric liver transplantation, Kaseje et al. showed that donor serum sodium levels of $\geqq 150-\mu \mathrm{mol} / \mathrm{L}$ were not associated with increased rates of mortality, rejection, or early biliary or infectious complications. However they found that the prothrombin time on post-transplant day 10 was significantly lower in the hypernatremia group [46]. Uribe et al. performed five pediatric liver transplants from donors with hypernatremia. The serum sodium levels were $169-193 \mathrm{mEq} / \mathrm{L}$ before medical management and between 157 and $172 \mathrm{mEq}$ at procurement. One patient died from sepsis due to biliary complications and another patient suffered acute liver failure, and required a re-transplantation two weeks after the initial transplant. They suggested that hypernatremic donors may be used for pediatric LT under special circumstances [47]. In conclusion we can say that hypernatremia, less than $160 \mathrm{mEq} / \mathrm{L}$ is not an absolute 
contraindication to accept a liver graft per se. However it is recommended to consider that an accumulation of risk factors might enhance their influence on the outcome.

\section{6) Donor liver steatosis}

Donor liver steatosis is a frequent finding during organ procurement. In the study of Briceno et al 120 patients who underwent OLT for HCV cirrhosis were evaluated. In $66 \%$ of cases mild to severe donor steatosis was found. Detailed results in the groups according to the degree of steatosis were the following: absent $(0 \%-10 \% ; \mathrm{n}=40)$, mild $(10 \%-30 \% ; \mathrm{n}=32)$, moderate $(30 \%-$ $60 \% ; \mathrm{n}=29)$, or severe $(>60 \% ; \mathrm{n}=19)$. Burra et al controlled 116 biopsies taken at the back table preparation, before implantation. No steatosis was seen in $50.9 \%$ of the biopsies, whereas steatosis was mild in $39.6 \%$ of the samples and moderate/severe in $9.5 \%$ of the samples. This was already reported by Busuttil et al in 2003 that hepatocytes are susceptible for ischemic reperfusion injury (IRI). During IRI many different pathophysiological pathways will be activated, for example activation of Kupffer cells and Ito cells, increasing production of free radicals, and reactive oxygen derivates. These processes will conclude to chemokine release, activation of polymorphonuclear cells, driving to an inflammatory-like cascade. This results in a decreased blood flow in the hepatic sinusoids. Diminished oxygen supply will lead to hepatocyte damage through apoptosis and necrosis, even in healthy livers. However this process will be much enhanced in steatotic grafts, where the microcirculation was already damaged by fat droplets and cellular oedema during cold ischemia. [48].

Liver steatosis has a multifactorial etiology and it is commonly seen in diabetic and obese patients as well in patients with alcohol abuse. Based on the histologic features liver steatosis can be classified as microvesicular or macrovesicular. Microvesicular steatosis appears as diffuse formation of small fat vacuoles surrounding the nucleus, it is usually associated with prolonged hospitalization and total parental nutrition, and sepsis, but in most cases it is reversible.

Macrovesicular steatosis is characterized by a single fat vacuole larger that nucleus, which displace the nucleus to the periphery. It is usually associated with obesity, diabetes, hyperlipidaemia and alcohol abuse. Usually both micro- and macrovesicular steatosis is present simultaneously at different degrees. Steatosis can be graded (quantified) based on histology as mild $(<30 \%)$, moderate $(30 \%-60 \%)$ and severe $(>60 \%)$. Microvesicular steatosis has limited influence on posttransplant liver graft function compared to macrovesicular steatosis, which is more often associated with graft dysfunction. Moreover, the grade of macrovesicular steatosis correlates with the incidence and severity of graft dysfunction. 
The estimation of the grade of steatosis before and at the time of organ procurement remains challenging. Prediction of the degree of steatosis based on the clinical and biochemical parameters is difficult, however a recent study by Cucchetti et al. showed that combination of BMI, elevation of ALAT, presence of type II diabetes mellitus, history of heavy alcohol consumption and ultrasonography signs of steatosis could accurately identify steatosis $>30 \%$, confirmed by liver biopsy [49]. A preliminary study evaluating the feasibility of transient elastography in the assessment of liver steatosis in potential deceased liver donors demonstrated promising results [50]. Even though the results of studies by Yersiz et al and Martins et al show good prediction of liver steatosis by the procuring surgeon based of gross appearance of the liver, especially if steatosis is $<30 \%$, liver biopsy remains the gold standard as an objective assessment of the degree of liver steatosis and it is recommended in any case of suspicion of steatosis [5156]. Nevertheless, a recent study by El-Badry et al. demonstrated significant intra-observer variability in the histologic assessment of liver steatosis among expert pathologists [57].

The impact of degree of liver steatosis in liver biopsy was studied by Sitzer et al. in 5051 donors in correlation with DRI [58]. Except for well-known factors from DRI such as donor age, CIT and DCD, donor liver macrovesicular steatosis was an additional factor that strongly associated with graft failure at 1 year after liver transplantation (LT). Steatotic livers have been reported to be more susceptible to cold ischemia injury and moderate to severe macrovesicular steatosis has been observed as the leading cause of severe liver preservation injury [3]. Others report about 225 consecutive liver transplants that were reviewed according to the intraorgan blood flow in association with mild $(<30 \%$, and moderate/severe $(>30 \%))$ macrosteatosis of the donor liver. Angele $M K$ et al report that organ blood flow was not affected by steatosis [59].

The use of grafts with moderate steatosis (30\%-60\%) remains a challenging issue, since the incidence of primary non function may reach $15 \%$, and the rate of delayed graft function approaches $35 \%$. Except when procurement is performed by an experienced transplant surgeon, no graft should be rejected solely on the basis of inspection. Biopsy should be viewed as a means for transplanting more organs. Recipient selection and minimal CIT are paramount to the successful utilization of moderately steatotic allografts as a period of delayed allograft function is expected [7].

Allocation of the steatotic grafts in the recipient with HCV-related liver requires some caution. The results of current studies are not univocal. Although previous studies suggested exacerbation of HCV recurrence in patients transplanted with steatotic grafts this finding was confirmed only in by Briceno et al., who showed more frequent and earlier HCV recurrence in recipients of 
moderately and severely steatotic grafts [60]. Two other studies demonstrated no impact of mild to moderate graft steatosis on HCV recurrence after LT [61,62]. Moreover, Burra et al. showed that even severe steatosis had no influence on progression to fibrosis in $\mathrm{HCV}+$ recipients and on 3-year patient survival [62]. In two Italian studies graft steatosis $>25 \%$ was found to be independent risk factor for biliary complications, especially for biliary strictures after OLT, however there was no obvious explanation for this finding [63,64]. According to Subramanian et al steatosis significantly influences post OLT HCV specific immune response and development of allograft fibrosis. Increasing grades of steatosis favours the development of predominant Th 17 type HCV specific immune response with concomitant suppression of Th1 (IFN-gamma) [65].

The Paris consensus meeting concluded that mild steatosis (30\%) has minimal impact on liver function post-transplantation, provided that CIT is short [7]. As a previous ELTR analysis had identified a cut-off of CIT $<12$ hours [66], the current recommendation is to keep total ischemia time below 12 hours although the precise threshold for improved outcome is unclear [67]. Liver grafts from elderly donors and/or donors with steatosis are even more affected by prolonged CIT and preservation injury. In this group, optimal liver function can be best achieved when CITs are kept less than 8 hours [7]. The ELTR survey showed that 5-year recipient survival was 57\% with CIT over 15 hours versus 64\% with CIT between 12 and 15 hours and 67\% with CIT below 12 hours [68].

In cases of donors with any risk for a chronic liver disease (anti-HCV, alcohol abuse) the identification and grading of fibrosis is expected from a biopsy [7]. Estimation of steatosis using haematoxylin and eosin ( $\mathrm{H} \& \mathrm{E})$-stained frozen section liver biopsy has been reported to be difficult and subjective [3]. Therefore the debate about whether and how to perform a biopsy is ongoing. To expedite allocation and minimize CIT, a uniformly recognized strategy for successful ECD utilization, histologic evaluation, is typically performed by local pathologists where donation occurs. A study designed to compare the results of frozen sections (FS) performed by local pathologists with the ones of permanent sections (PS) evaluated by experienced hepatopathologists. Its seems that comparing FS and PS the evaluation of fibrosis and necrosis exceeded $80 \%$ correlation, and the estimation of macrovesicular and microvesicular steatosis approximated $70 \%$ agreement. Agreement between FS reports by local pathologists at the donor hospital and PS evaluated by experienced hepatopathologists was high, and significant discrepancies were rare. This evaluation suggests that biopsy misinterpretation is unlikely and should not present a significant impediment to further ECD expansion and increased allograft 
travel [53]. A prerequisite to better understand the impact of graft steatosis on outcome will be to obtain routine donor liver biopsy at the time of harvest [13].

In conclusion, the presence of steatosis in the donor liver graft is an independent and determinant risk factor for the postoperative graft function and outcome. Steatosis makes the hepatocytes susceptible to further injuries, like ischemia, or virus positive environment. While microsteatosis is not a risk factor per se, macrosteatosis, especially if this is moderate, or severe, graded by histology, can be a cause of graft failure. The gold standard of the diagnosis is the biopsy that is recommended in all doubtful cases. Non-conventional factors of an Extended Criteria Donor

This chapter briefly discuss „non-conventional” ECD. parameters. These are the hepatitis C and $\mathrm{B}$ infected grafts, and the donors after cardiac death. We call them non-conventional since they were not involved in the assessment of all (also non-ECD) donors earlier, and their implementation as a part of expanding the donor pool..

\section{1) Hepatitis $\mathbf{C}$ and hepatitis $B$ infected grafts}

Organ shortage provoked the transplant community to expand the donor pool with the hepatotrop virus positive donors. This is consent that HCV and HBV positive donors mean a higher risk in liver transplantation. On the other hand the largest population of recipients waiting for a liver is also the HVC/HBV positive patients. Thuss it is fair to discuss the assessment, and allocation of these donors. The reactivation / recurrence of HCV and HBV will be discussed in the second part of this review.

\section{a. Anti-HCV positive donors}

First, HCV+ donors were rejected due to the concerns of viral transmission and accelerated HCV recurrence. Preliminary reports have been published with short follow-ups and no differences in outcomes with the use of anti-HCV-positive grafts [69]. However, it has been clearly shown that the survival and progression of HCV disease is similar to HCV negative allografts [70]. Therefore, HCV+ grafts are increasingly used by transplant centres [71].

In a study by Northup et al., data of 19,496 HCV positive recipients and $934 \mathrm{HCV}$ positive donations were analysed using the US OPTN Scientific Registry database [72]. They have reported good long-term outcomes using $\mathrm{HCV}+$ liver grafts, finding that mean survival times in $\mathrm{HCV}+$ recipient / $\mathrm{HCV}+$ donor was 9.8 years compared to 10.6 years for $\mathrm{HCV}+$ 
recipient/HCV- donor. In addition, after adjusting for factors known to affect post-transplant survival, the hazard ratio was equivalent for both groups [72].

Similar conclusions have been made by Burra et al. in 2011 after analysing the UNOS database including 63,149 liver transplants (61,905 donors HCV-; 1,244 donors HCV+) from 1987 to 2007. In the case-controlled matched cohort, HCV status was shown to have no significant effect on overall mortality or graft survival. It should be mentioned that nearly one-third of HCV+ allografts were transplanted into $\mathrm{HCV}$ - recipients $(30.7 \%)$ in this study, concluding a potential benefit of $\mathrm{HCV}+$ allografts in certain circumstances and recipients (acute liver failure or extreme illness without a correspondingly appropriate MELD score) [71].

In a European multicentre study by Ballarin et al. data of 694 patients with HCV-related cirrhosis were analysed. They also found that the use of anti-HCV-positive donor was not a significant risk factor regarding patient and graft survival for HCV positive patients. However, recipients of antiHCV-positive donor grafts had a higher incidence and histology-proven recurrence of hepatitis $\mathrm{C}$ than HCV-/HCV+ group, although it did not reach statistical significance $(\mathrm{P}=0.07)$. Further it has been also shown that HCV-RNA positivity likely represents a predictive factor for development of recurrent hepatitis $C$ after transplantation, such as steatosis and aging [69].

It has been reported by O'Leary et al that 53\% (17/32) of HCV seropositive donors are HCVRNA negative. Although in only a small number, it has shown that graft and patient survival, as well as fibrosis progressions were unchanged in recipients of viremic and aviremic donors. Another finding was that patients infected with non-1 genotypes would have a disadvantage if they are given a genotype 1 infected graft and genotype 1 dominated. They also suggested to allocate HCV antibody-positive donors to genotype 1 infected recipients at this time [73].

In conclusion, the use of $\mathrm{HCV}+$ grafts for $\mathrm{HCV}+$ recipients is comparable in outcome even in the long-term. Behind these findings a potential role of the relatively large proportion of HCV seropositive but HCV RNA negative liver grafts could be mentioned. It seems that the leading risk factor for recurrence of hepatitis $\mathrm{C}$ with an anti-HCV-positive graft is HCV-RNA positivity. The allocation of HCV-seropositive donors to genotype 1 infected patients could be suggested.

\section{b. Anti-HBc positive donors}

The major limitation to using liver grafts from HBV core antibody-positive (anti-HBc) but HBV surface antigen ( $\mathrm{HBs} \mathrm{Ag}$ ) negative donors is the potential risk of de novo HBV infection after transplantation [74]. However, an overall low risk of HBV reactivation has been shown when 
treated with nucleos(t)ide analogues and hepatitis B immunoglobulin (HBIG), therefore, anti$\mathrm{HBc}$ positive grafts are no longer rejected in many transplant centres [75,76]. In HBV related cirrhosis, anti-HBc donors are frequently used as they require life-long anti-HBV prophylaxis in any case and postOLT outcomes have not been affected [74]. Allocation policy and prophylactic protocols are the main issues in this field.

In a study by $Y u$ et al. [77], similar survival rates have been shown in recipients with anti-HBC positive grafts in comparison to the ones with anti-HBc negative grafts. The use of anti- $\mathrm{HBc}$ positive grafts appeared to affect recipients without anti-HBs more adversely than those with anti-HBs prior to OLT [77]. A prospective multicentre study by Angelico et al. showed that the use of anti-HBc positive donor grafts is associated with excellent results when they are transplanted to $\mathrm{HBsAg}$ positive recipients, receiving standard prophylaxis against HBV. Conversely, the use of anti-HBc positive donor grafts in $\mathrm{HBs} A g$ negative recipients requires attention, as it may be associated with suboptimal survival, especially in patients with high MELDs and/or additional risk factors. The presence of anti-HBc in HBsAg negative recipients does not seem to be protective and cannot justify the allocation of anti-HBc positive donor grafts to these patients [78]. MacConmara et al [79] reported similarly good results. All but one of the $\mathrm{HBcAb}+$ organ recipient deaths occurred in patients with MELD scores of $>30$ at transplantation and the difference was apparent when this group was compared with $\mathrm{HBcAb}+$ organ recipients with lower MELD scores, and also when it was compared with control recipients with MELD scores $>30$. None of their patients had de novo HBV infection during study period using prophylaxis with HBIG for 3 months and subsequently provide lifetime antiviral therapy.

Brock et al. evaluated $958 \mathrm{HBsAg}$ negative recipients of anti-HBc positive donors. Patients were classified on the basis of whether they received HBIG alone, Lamivudine alone, both, neither, or were missing this information. They observed that HBIG-only therapy had improved patient survival relative to Lamivudine only prophylaxis. Similarly, improved graft survival was observed for HBIG vs. Lamivudine-only recipients, though the result was not statistically significant. The combination therapy group (HBIG and Lamivudine) was also observed to have longer patient survival relative to Lamivudine-only therapy [80].

Loggi et al. reported that the use of HBsAg positive grafts is a safe procedure with appropriate antiviral therapy. 10 patients were studied using HBsAg positive grafts for OLT in patients with serological evidence of past hepatitis B infection. None of the patients developed any sign of HBV-related disease compromising the graft or patient survival. In addition, they noticed that 
HBsAg positive patients, even when treated with nucleos(t)ide analogues and HBIG were unable to clear the virus. Conversely, patients who previously controlled HBV, even in the case of HBsAg reappearance, were able to control it again [76].

In a review paper by Skagen et al. analysing 26 studies including the risk of de novo hepatitis B from $\mathrm{HBcAb}$ positive donors, found that the rate of de novo hepatitis $\mathrm{B}$ was the highest for HBV naïve recipients of anti-HBc positive liver donors. They have recommended utilizing longterm lamivudine alone in recipients who are HBV naïve and have isolated anti-HBs. Recipients with anti-HBc positivity should not be offered prophylaxis but should undergo close virologic and serologic surveillance with monitoring of HBV DNA, HBsAg, and liver enzymes [81].

In conclusion, liver grafts from anti-HBc positive donors should be allocated to recipients with prior HBV exposure. The presence of anti-HBs seems to protect from de novo HBV infection and both anti-HBc and anti-HBs positive recipients seem to represent a group that can safely receive anti-HBc positive liver grafts without any post-transplant HBV prophylaxis [74]. According to MacConmara et al liver transplantation using HBcAb t grafts can be performed with similar outcomes to transplants that use $\mathrm{HBcAb-grafts.} \mathrm{[79].}$

\section{2) Donors after cardiac death}

The first human LTs were performed from donation after cardio-circulatory death (DCD) in the 1960s [82]. In the United Kingdom, liver transplantation after DCD organs has increased steadily over the last few years and now accounts for 20\% [83]. DCD is based on cardiopulmonary criteria for death rather than neurologic criteria, when WIT is typically prolonged [70]. The use of these liver grafts has been associated with higher rates of graft failure and biliary complication, particularly ischemic type cholangiopathy, compared with donation after brain death (DBD) allografts [84]. Optimum outcome has been shown if the WIT does not exceed 30 minutes, the CIT is limited to less than 8 hours, and younger donors being used ( $<50$ years) [71]. Nguyen et al. examined long-term outcomes in 19 DCD donors, 234 standard criteria donors (SCD) and 214 ECD donations. Evaluating these results we have to take the smaller case number of the DCD group into account. They found no difference in the rate of primary non-function and biliary complications comparing DCD with SCD and ECD. The overall one, two-, and five-years DCD graft and patient survival was $73.7 \%, 68.4 \%$, and $63.2 \%$, and $89.5 \%, 89.5 \%$, and $89.5 \%$, respectively. DCD graft survival was similar to graft survival of SCD and ECD in non-hepatitis C virus $(\mathrm{HCV})$ recipients $(\mathrm{p}>0.370)$. In contrast, DCD graft survival was significantly reduced in HCV recipients [85]. Skaro et al reports about 32 DCD and 237 SCD donations. In their findings 
DCD livers had a 2.1 times greater risk of graft failure, a 2.5 times greater risk of relisting, and a 3.2 times greater risk of retransplantation compared with DBD recipients. DCD recipients had a $31.6 \%$ higher incidence of biliary complications and a 35.8\% higher incidence of ischemic cholangiopathy [86]. A large US study by Mathur et al. reported good outcomes using DCD grafts. Three years post-DCD liver transplant, $64.9 \%$ of recipients were alive with functioning grafts, $13.6 \%$ required retransplant and $21.6 \%$ died. They have shown that each hour increase in CIT was associated with $6 \%$ higher graft failure rate (OR 1.06, $\mathrm{p}<0.001)$ and donor WIT $\geq 35$ min significantly increased graft failure rates $(\mathrm{OR} 1.84, \mathrm{p}=0.002)$. Recipient predictors of mortality were age $\geq 55$ years, hospitalization at transplant and retransplantation (all, $\mathrm{p} \leq 0.006$ ). Donor weight $>100 \mathrm{~kg}$ and CIT also increased patient mortality (all, $\mathrm{p} \leq 0.035$ ) [87]. Abou Abbass et al reported a high prevalence of biliary complications with a new and wide spectrum of clinicopathologic findings about 26 DC OLTs in 2010. Biliary complications occurred in 46\%, and retransplantation rate was 23\% [88]. Bartlett et al reported 14 pediatric cases with DCD grafts. Livers were transplanted as a whole organ (4), reduced graft (8), formal split (1) or auxiliary transplant (1). Compared to DBD recipients ASAT was significantly higher on the first three post-operative days and there was no difference in the INR, bilirubin or $\gamma$ GT out to 12 months. There were no biliary or vascular complications and patient and graft survival is $100 \%$ at a median follow-up of 41.8 months (1.7-74 months) [89].

\section{a. HCV recurrence and DCD donation}

Although in limited number, recent studies aimed to examine the impact of DCD use on the outcome of OLT in HCV positive patients. The summarized results are shown in Table 2.

Yagci et al analysed data of $14 \mathrm{DCD} / \mathrm{HCV}$ and $188 \mathrm{DBD} / \mathrm{HCV}$ patients and reported a significantly lower overall patient and graft survival rate for DCD patients compared to the DBD patient group. In addition, the incidence of liver abscess with ischemic-type biliary stricture was higher in recipients from DCD as compared with DBD (42\% vs $2 \%$ ). The incidences of hepatic artery thrombosis (HAT), portal vein thrombosis, and PNF were similar between the DCD and DBD groups [90]. Tao et al. examined the impact of DCD livers on patient and graft survival in $\mathrm{HCV}$ infected patients and compared the severity of their HCV recurrence to that of matched group of patients who received DBD livers. DCD patients had significantly higher peak ASAT and ALAT levels in the early postoperative period suggesting a higher probability of ischaemia/reperfusion injury in the DCD grafts. Despite these findings no difference was found in DCD vs DBD groups regarding time and severity of HCV recurrence (postoperative HCV 
RNA levels, SVR rate, HCV-related graft failure leading to retransplantation or death, 4/6 fibrosis.) [91].

In a paper by Mawardi at al. graft outcomes in HCV and non-HCV liver transplant recipients of DCD grafts were analysed. A lower rate of biliary complication was seen in the HCV group when compared with the non-HCV group $(\mathrm{p}=0.21)$. An excellent patient and graft survival was observed in the non-HCV recipients of DCD grafts (100 and $92 \%$, respectively) compared to (78, $67 \%$ ) in HCV recipients. The 33\% (3/9) of the HCV recipients of DCD grafts suffered graft loss, two from fatal aggressive fibrosing cholestatic $(\mathrm{FCH}) \mathrm{HCV}$ and one due to ischemic cholangiopathy [92]. Similarly to previous authors, Hernandez-Alejandro et al. found DCD graft as a risk factor for earlier and more aggressive HCV recurrence as revealed in the finding that $47 \%$ of our HCV recipients of DCD grafts were documented to have significant fibrosis (stage 2) within the first transplant year compared with a significantly smaller number $(10 \%)$ in the matched control group. When comparing HCV DCD recipients with HCV DBD recipients, a significant decreased graft survival, higher rate of $\mathrm{HCV}$ recurrence at 3 months and an increased rate of severe HCV recurrence within the first year were found. Protocol biopsies performed in HCV DCD liver transplant recipients showed histologic progression from time 0 to 3 months and then 1year, lending support that this was due to $\mathrm{HCV}$ progression and not a static process secondary to ischemia/reperfusion damage obtained at the time of liver procurement [93].

In contrast, Taner et al reported similar graft and patient survival rates of HCV patients regardless of the graft type that they received and concluded an advantage of DCD graft utilization in HCV patients, and only the MELD score at the time of OLT and CMV infection within the first postoperative year affected graft survival. Among the factors studied for fibrosis progression, HCV genotype 1 was as a significant factor, whereas moderate to severe acute rejection episodes within the first year approached statistical significance. It should bet noticed that in this centre donors older than 60 years have not been used for HCV patients. As such, HCV patients are limited to younger donors, so their waiting times are longer than those of patients with other etiologies of liver disease. As a result, DCD grafts were used more often in HCV patients $(51 \%)$ compared to overall percentage of HCV patients in our program (35\%) [94] .

UNOS data analyses regarding HCV recurrence and DCD donation have been reported by Uemura et al. in 2012. DCD liver transplantation achieved inferior graft survival compared to DBD donor transplants regardless of HCV and non-HCV status and the difference in graft survival between DCD donor and DBD donors was significantly less in HCV patients compared to non-HCV patients. One possible explanation for their finding was the effect of a younger age 
for DCD donors. A favourable outcome can be expected if a DCD liver is transplanted in a favourable condition, meaning WIT less than 30 minutes, CIT less than 8-10 hours, and donor age less than 50-60 years. However, due to the lack of recurrent HCV data (liver biopsy and HCV PCR), firm conclusions regarding HCV recurrence after DCD donation could not been made [95].

\section{b. DCD donation and additional ECD factors}

Earlier, DCD was defined as an independent factor itself. Therefore the common policy was not to combine DCD with other ECD factors. However Tariciotti $L$ et al focused on DCD liyer grafts in their series where "extended" criteria were applied (donor age $>60$ yrs., BMI>30, donor WIT $>30$ min., CIT $>8$ hours). The 1 -year patient and graft survival was $88 \%$ and $82 \%$ for the standard group vs. $90 \%$ and $90 \%$ for the extended one. The rate of biliary complications did not differ [96]. The dilemma between diminishing the WLM and putting the recipients on a higher risk of graft failure will then be complicated by the question: on what price? Broombead HD et al focused on the need of perioperative resources in case of DCD OLTs: the increased prevalence of reperfusion syndrome $(\mathrm{P}<0.001)$, a prolonged heparin effect $(\mathrm{P}=0.01)$, a greater incidence of hyperfibrinolysis $(\mathrm{P}=0.002)$, longer periods of postoperative ventilator use $(\mathrm{P}=0.03)$, and vasopressor support $(P=0.002)$, and a prolonged ICU of stay $(p=0.02)$.was characteristic to DCD group. Together with an overall poorer quality of DCD grafts, their advice is then to regard on donation after brain death (DBD) as a first resort [83]

The term 'controlled' and 'uncontrolled' for DCDs were not used at the Maastricht workshop but added later. For the uncontrolled DCD donor, death was either confirmed outside of hospital (Maastricht I) but the donor was still brought to hospital; or death was declared after unsuccessful resuscitation after witnessed cardiac arrest (Maastricht II) usually in the Accident and Emergency unit [97]. The Maastricht type II DCD (sudden- out-hospital cardiac arrest) uncontrolled donation increases donor risk extremely, and makes it impossible to carry out a safety procedure in the majority of the cases. Fondevilla et al revised 400 potential M-II donors of whom only 34 liver transplants were performed ( $9 \%$ ), with one-year recipient and graft survivals of $82 \%$ and $70 \%$, respectively [98].

In a recent and large study based on the UNOS/OPTN database, 85148 patients were found to receive a liver graft from a DBD, and 2351 from a DCD procedure. Cumulative survival was significantly worse for DCD, but only in adults. Pediatric recipients had similar survival in both groups. The optimal value for risk factors were recipient age $<50$ yrs., INR $<2,0$, albumin $>3,5$ 
$\mathrm{mg} / \mathrm{dL}, \mathrm{CIT}<8$ hours, and donation WIT $<20$ min [99]. Jay CL et al studied the comparative effectiveness of DCD vs. DBD OLT. A Markov model was constructed to compare undergoing DCD transplantation with remaining on the wait-list until death or DBD liver transplantation. DCD liver transplantation resulted in inferior survival for patients with a MELD score $<15$ and HCC patients receiving MELD exception points, but provides a survival benefit to patients with a MELD score $>20$ and to HCC patients without MELD exception points. The incremental cost-effectiveness ratio (ICER) was $>\$ 2,000,000$ /quality-adjusted life years (QALY) for MELD $<15$, and \$478,222/QALY and \$120,144/QALY, for MELD 21-30, and over 30, respectively. [100]. In summary the recent experience with controlled donation after cardiac death are encouraging. However, in this context, other risk factors (old age, CIT, WIT, steatosis) for graft failure should be avoided. Recent data regarding the use of these grafts in HCV patients are somewhat controversial. One potential explanation for worse outcomes in HCV could be the higher susceptibility to ischemic injury and cellular proliferation as a consequence.

Optimal utilization of ECD liver grafts is based on the best estimation of liver quality, proper recipient selection, management to minimalize the travel injury, avoidance of further surgical fails, and a high quality ICU care of the recipient. An ideal recipient group for donors $>70$ years has been described as patients $>45$ years old, with body mass index $<35$; non-HCV+, non-UNOS status 1 registration; first transplants with a CIT $<8$ hours. OLT using grafts showing microvesicular steatosis seems to be safe regardless of its severity, while the outcome of OLT with macrosteatotic grafts depends on the severity of the fat infiltration. McCormack et al. showed that LT with grafts with steatosis $>60 \%$, (despite the higher incidence of EAD) can achieve excellent patient and graft survival when these grafts are allocated in low risk recipient [101]. The proper allocation of steatotic grafts was confirmed by Dutkowski et al., who analysed the two largest liver transplant databases in Europe and in the US. Graft with $<30 \%$ steatosis can be used safely up to BAR (Balance of Risk) score of 18 or less, however if graft steatosis exceeds $30 \%$ acceptable outcome can be achieved only if BAR score is less than 9 score [102]. Also the use of low score ECDs in recipients with moderate cirrhosis and HRS is a good option. However, grafts from moderate-to-severe steatosis and those from aged donors must be carefully allocated in candidates with HRS. Allocation of some marginal donors may not cause any debate: HCV+ livers must be transplanted to $\mathrm{HCV}+$ recipients and anti-HBc+ grafts must be initially transplanted to $\mathrm{HBV}+$ patients, but may be transplanted to $\mathrm{HBV}$-negative recipients provided antiviral therapy is used after transplantation. Allocation systems have different dimensions: for 
example.an extra regional sharing in Eurotransplant represents much less distance in comparison with United States. A formula to calculate the DRI was developed. It includes only donor and transplant parameters found to significantly influence outcomes after liver transplantation in a multivariate analysis of a large cohort (20,023 transplants) from the Scientific Registry of Transplant Recipients database. These parameters are as follows: the donor's age, race, height, and cause of death; the split liver donation status; the DCD status; the type of allocation (local, regional, or national); and the CIT. The mean DRI was remarkably higher in the Eurotransplant region versus OPTN (1.71 versus 1.45), and this indicated different donor populations [19]. Regarding the non-liver field of transplantation, HCV positive donors are also used in kidney transplantation, with promising results. Analysing more than 1600 kidney transplantations, Scalea et al found that $\mathrm{R}+/ \mathrm{D}+$ patients spent less time on the transplant waitlist, which contributed to improved death censored graft survival when compared with $\mathrm{R}+/ \mathrm{D}$-patients (103). Others found that patients receiving ECD transplants had lower allograft survival after seven years than patients receiving transplants from standard criteria donors (SCD; $80 \%$ v $88 \%, \mathrm{P}<0.001$ ). Analysing 6890 patients they concluded that of the 916 used, CED kidney, the circulating DSA, and prolonged CIT ( $>12$ hours) were the main composites for an ECD in kidney transplantation (104). This is clear that measures for an ECD are different in liver and kidney transplantation. This is common that donor age, and HCV/HBV positivity are not absolute limiting factors any more. Organ specific influencing factors are the donor specific DSA for kidney, and the steatosis for liver transplantation. This is typical to all organ transplant programs that the combination or cumulative presence of certain factors will increase the risk of graft failure significantly. Therefore the suggested pathway of organ quality assessment consists of three steps: obtain the most information (e.g. biopsy in questionable cases), consider that co-existing factors can potentiate each other (e.g. a 56 year old $\mathrm{HCV}$ positive donor, with an increased $\mathrm{Na}+$, and enlarged liver on ultrasound), and finally to consider the potential homeostatic reserves capacity of the recipient (e.g. an ECD liver can be fit for a patient with an HCC, without severe cirrhosis, but not for an acute liver failure). As a fourth factor a surgeon always should take into account that additive technical problems might worsen the situation. Therefore an ECD liver graft with an anatomical variation or injury that requires reparation will increase the risk additive complications like arterial thrombosis.

\section{VI)} Five Year View

In the next five years, it is anticipated that the use of $\mathrm{HCV}$ positive donors will be widely accepted for HCV positive recipients. The use of HBV positive donors will not be restricted to HBV positive, but also to $\mathrm{HBV}$ negative candidates with a proper nucleoside treatment. 
Hypernatremic donors may be useful for liver transplantation in the countries around the world that are affected by organ shortages. The development of ICU management will open this narrow pathway together with the usage of machine perfusion that is going to be discussed later.

Additionally, online evaluation of liver-graft biopsies will be organized through a 24 hour service in proper centres to improve the utilisation of steatotic grafts, by ruling out macrosteatosis. The upper age limit will be pushed fowards together with the extension of old for old programs. Old but otherwise good donor organs will be allocated regionally, to diminish other factors.Regarding the open network of the internet, patient consent to use an ECD will be a hot topic in the next five years.

\section{VII) Key issues}

1) Donor Risk Index has the most relevant association with the majority of outcome parameters, as it is validated by ELITA based on OPTN (UNOS) parameters.

2) Donor age, and elevated liver function tests are not absolute contraindications. Biological age might differ from administrative one. The management of donor on the ICU have more impact on later results.

3) Donor liver steatosis is a real challenge to assess. The ideal position is to have the biopsy and histology in the actual „tool kit”. Macrovesical steatosis is an independent risk factor for graft failure. It is a relative contraindication to OLT if its grade is moderate, or severe, Microsteatosis might also be a risk factor, when it is $20 \%$ or more. When histology cannot be performed other parameters must be considered as parallel or additive risk factors. Steatotic livers should not be transplanted to $\mathrm{HCV} / \mathrm{HBV}$ positiye or kidney function impaired recipients

4) Hepatitis $C$ and B positive donors can be used safely for $\mathrm{HCV} / \mathrm{HBV}$ positive recipients. It seems that the leading risk factor for recurrence of hepatitis $C$ with an anti-HCV-positive graft is HCV-RNA positivity. The allocation of HCV-seropositive donors to genotype 1 infected patients seems to be safe and also an effective way to expand the donor pool.

5) Hypernatremic donors were previously considered as ECDs, because high serum sodium levels have been associated with decreased graft survival and function. It was thought that decreased graft survival and function were caused by cellular swelling, which occurs as a result of transition from an extracellular hypernatremic state to intracellular osmolality, these phenomenon lead to poor results. However, recent studies have revealed that hypernatremia is not correlated with graft survival and function. 


\section{Financial and competing interests disclosure}

The authors have no relevant affiliations or financial involvement with any organization or entity with a financial interest in or financial conflict with the subject matter or materials discussed in the manuscript. This includes employment, consultancies, honoraria, stock ownership or options, expert testimony, grants or patents received or pending, or royalties.

\section{References}

Reference annotations

* Of interest

** Of considerable interest

1. Mirza DF, Gunson BK, Da Silva RF, Mayer AD, Buckels JA, McMaster P. Policies in Europe on "marginal quality" donor livers. Lancet, 344(8935), 1480-1483 (1994).

2. Barshes NR, Horwitz IB, Franzini L, Vierling JM, Goss JA. Waitlist mortality decreases with increased use of extended criteria donor liver grafts at adult liver transplant centers. Am J Transplant, 7(5), 1265-1270 (2007).

3. Nickkholgh A, Weitz J, Encke J et al. Utilization of extended donor criteria in liver transplantation: a comprehensive review of the literature. Nephrol Dial Transplant, 22 Suppl 8, viii29-viii36 (2007).

4. Northup PG, Pruett TL, Kashmer DM, Argo CK, Berg CL, Schmitt TM. Donor factors predicting recipient survival after liver retransplantation: the retransplant donor risk index. Am J Transplant, 7(8), 1984-1988 (2007).

5. Schemmer P, Nickkholgh A, Hinz U et al. Extended donor criteria have no negative impact on early outcome after liver transplantation: a single-center multivariate analysis. Transplant Proc, 39(2), 529-534 (2007).

Afonso RC, Hidalgo R, Paes AT et al. Impact of cumulative risk factors for expanded criteria donors on early survival after liver transplantation. Transplant Proc, 40(3), 800-801 (2008).

7. Durand F, Renz JF, Alkofer B et al. Report of the Paris consensus meeting on expanded criteria donors in liver transplantation. Liver Transpl, 14(12), 1694-1707 (2008).

8. $\quad * *$ Feng S, Lai JC. Expanded criteria donors. Clin Liver Dis, 18(3), 633-649 (2014). 
9. Chen H, Peng CH, Shen BY et al. Multi-factor analysis of initial poor graft function after orthotopic liver transplantation. Hepatobiliary Pancreat Dis Int, 6(2), 141-146 (2007).

10. Nemes B, Gelley F, Zadori G et al. [The role of marginal donors in liver transplantation. The Hungarian experience]. Orv Hetil, 150(49), 2228-2236 (2009).

11. Lucidi V, Lemye AC, Baire L et al. Use of marginal donors for liver transplantation: a single-center experience within the Eurotransplant patient-driven allocation system. Transplant Proc, 39(8), 2668-2671 (2007).

12. Silberhumer GR, Pokorny H, Hetz $\mathrm{H}$ et al. Combination of extended donor criteria and changes in the Model for End-Stage Liver Disease score predict patient survival and primary dysfunction in liver transplantation: a retrospective analysis. Transplantation, 83(5), 588-592 (2007).

13. Mullhaupt B, Dimitroulis D, Gerlach JT, Clavien PA. Hot topics in liver transplantation: organ allocation--extended criteria donor--living donor liver transplantation. J Hepatol, 48 Suppl 1, S58-67 (2008).

14. Wu TJ, Lee CF, Chou HS, Yu MC, Lee WC. Suspect the donor with potential infection in the adult deceased donor liver transplantation. Transplant Proc, 40(8), 2486-2488 (2008).

15. Detry O. Extended criteria donors: the case for liver procurement in donors with a central nervous system malignancy. Liver Transpl, 15(6), 670-671 (2009).

16. Gordon Burroughs S, Busuttil RW. Optimal utilization of extended hepatic grafts. Surg Today, 39(9), 746-751 (2009).

17. Nafidi O, Marleau D, Roy A, Bilodeau M. Identification of new donor variables associated with graft survival in a single-center liver transplant cohort. Liver Transpl, 16(12), $1393-1399(2010)$.

18. Hong JC, Yersiz H, Kositamongkol P et al. Liver transplantation using organ donation after cardiac death: a clinical predictive index for graft failure-free survival. Arch Surg, 146(9), 1017-1023 (2011).

19. Blok JJ, Braat AE, Adam R et al. Validation of the donor risk index in orthotopic liver transplantation within the Eurotransplant region. Liver Transpl, 18(1), 112-119 (2012). 
20. Silberhumer GR, Rahmel A, Karam V et al. The difficulty in defining extended donor criteria for liver grafts: the Eurotransplant experience. Transpl Int, 26(10), 990-998 (2013).

21. Bruzzone P, Giannarelli D, Adam R. A preliminary European Liver and Intestine Transplant Association-European Liver Transplant Registry study on informed recipient consent and extended criteria liver donation. Transplant Proc, 45(7), 2613-2615 (2013).

22. Arjona-Sanchez A, Sanchez-Hidalgo JM, Ciria-Bru R et al. Prediction model to discard a priori liver allografts. Transplant Proc, 46(9), 3076-3078 (2014).

23. Zeeh J, Platt D. The aging liver: structural and functional changes and their consequences for drug treatment in old age. Gerontology, 48(3), 121-127 (2002).

24. Nardo B, Masetti M, Urbani L et al. Liver transplantation from donors aged 80 years and over: pushing the limit. Am J Transplant, 4(7), 1139-1147 (2004).

25. Serrano MT, Garcia-Gil A, Arenas J et al. Outcome of liver transplantation using donors older than 60 years of age. Clin Transplant, 24(4), 543-549 (2010).

26. Fruhauf NR, Fischer-Frohlich CL, Kutschmann M, Schmidtmann I, Kirste G. Joint impact of donor and recipient parameters on the outcome of liver transplantation in Germany. Transplantation, 92(12), 1378-1384 (2011).

27. Kim DY, Moon J, Island ER et al. Liver transplantation using elderly donors: a risk factor analysis. Clin Transplant, 25(2), 270-276 (2011).

28. Saidi RF. Utilization of expanded criteria donors in liver transplantation. Int J Organ Transplant Med, 4(2), 46-59 (2013).

29. Ghinolfy D, Marti J, De Simone P et al. Use of octogenarian donors for liver transplantation: a survival analysis. Am J Transplant, 14(9), 2062-2071 (2014).

30. Radunz S, Paul A, Nowak K, Treckmann JW, Saner FH, Mathe Z. Liver transplantation using donor organs with markedly elevated liver enzymes: how far can we go? Liver Int, 31(7), 1021-1027 (2011).

31. Hoyer DP, Paul A, Saner F et al. Safely expanding the donor pool: brain dead donors with history of temporary cardiac arrest. Liver Int, (2014). 
32. Mangus RS, Kubal CA, Fridell JA, Pena JM, Frost EM, Joseph Tector A. Alcohol abuse in deceased liver donors: impact on post-transplant outcomes. Liver Int, 35(1), 171-175 (2015).

33. Avolio AW, Agnes S, Magalini SC, Foco M, Castagneto M. Importance of donor blood chemistry data (AST, serum sodium) in predicting liver transplant outcome. Transplant Proc, 23(5), 2451-2452 (1991).

34. Gonzalez FX, Rimola A, Grande L et al. Predictive factors of early postoperative graft function in human liver transplantation. Hepatology, 20(3), 565-573 (1994).

35. Figueras J, Busquets J, Grande L et al. The deleterious effect of donor high plasma sodium and extended preservation in liver transplantation. A multivariate analysis.

Transplantation, 61(3), 410-413 (1996).

36. Totsuka E, Dodson F, Urakami A et al. Influence of high donor serum sodium levels on early postoperative graft function in human liver transplantation: effect of correction of donor hypernatremia. Liver Transpl Surg, 5(5), 421-428 (1999).

37. Totsuka E, Fung U, Hakamada K et al. Analysis of clinical variables of donors and recipients with respect to short-term graft outcome in human liver transplantation. Transplant Proc, 36(8), 2215-2218 (2004).

38. Powner DJ. Factors during donor care that may affect liver transplantation outcome. Prog Transplant, 14(3), 241-247; quiz 248-249 (2004).

39. Tector AJ, Mangus RS, Chestovich P et al. Use of extended criteria livers decreases wait time for liver transplantation without adversely impacting posttransplant survival. Ann Surg, 244(3), 439-450 (2006).

40. Renz JF, Kin C, Kinkhabwala M et al. Utilization of extended donor criteria liver allografts maximizes donor use and patient access to liver transplantation. Ann Surg, 242(4), 556563; discussion 563-555 (2005).

41. Akoad M, Wagener M, Francis F, Ahmed J, Ulizio D, Cacciarelli TV. Outcome of imported liver allografts and impact on patient access to liver transplantation. Transplant Proc, 38(10), 3564-3566 (2006). 
42. Cywinski JB, Mascha E, Miller C et al. Association between donor-recipient serum sodium differences and orthotopic liver transplant graft function. Liver Transpl, 14(1), 59-65 (2008).

43. Mangus RS, Fridell JA, Vianna RM et al. Severe hypernatremia in deceased liver donors does not impact early transplant outcome. Transplantation, 90(4), 438-443 (2010).

44. Goldaracena N, Quinonez E, Mendez P et al. Extremely marginal liver grafts from deceased donors have outcome similar to ideal grafts. Transplant Proc, 44(7), 2219-2222 (2012).

45. Khosravi MB, Firoozifar M, Ghaffaripour S, Sahmeddini MA, Eghbal MH, Early outcomes of liver transplants in patients receiving organs from hypernatremic donors. Exp Clin Transplant, 11(6), 537-540 (2013).

46. Kaseje N, Luthold S, Mentha G et al. Donor hypernatremia influences outcomes following pediatric liver transplantation. Eur J Pediatr Surg, 23(1), 8-13 (2013).

47. Uribe M, Alba A, Gonzalez G et al. Pediatric liver transplant outcome using severe hypernatremic donors. Transplant Proc, 45(10), 3726-3727 (2013).

48. Busuttil RW, Tanaka K. The utility of marginal donors in liver transplantation. Liver Transpl, 9(7), 651-663 (2003).

49. Cucchetti A, Vivarelli M, Ravaioli M et al. Assessment of donor steatosis in liver transplantation: is it possible without liver biopsy? Clin Transplant, 23(4), 519-524 (2009).

50. Pichon N, Loustaud-Ratti V, Clavel M, Carrier P, Amiel JB, Labrousse F. Value of liver stiffness measured by transient elastography in the liver transplant pre-operative evaluation of the potential deceased liver donors: preliminary study. Clin Transplant, 25(2), E205-210 (2011).

51. *Yersiz H, Lee C, Kaldas FM et al. Assessment of hepatic steatosis by transplant surgeon and expert pathologist: a prospective, double-blind evaluation of 201 donor livers. Liver Transpl, 19(4), 437-449 (2013).

52. Martins AM, Coelho GR, Marques GA, Moraes MO, Valenca Jr JT, Garcia JH. Hepatic steatosis assessment: a comparative study between surgeon evaluation and forward histopathologic findings. Arq Gastroenterol, 50(1), 15-18 (2013).

53. Lo IJ, Lefkowitch JH, Feirt $\mathrm{N}$ et al. Utility of liver allograft biopsy obtained at procurement. Liver Transpl, 14(5), 639-646 (2008). 
54. Fiorentino M, Vasuri F, Ravaioli M et al. Predictive value of frozen-section analysis in the histological assessment of steatosis before liver transplantation. Liver Transpl, 15(12), 1821-1825 (2009).

55. Biesterfeld S, Knapp J, Bittinger F, Gotte H, Schramm M, Otto G. Frozen section diagnosis in donor liver biopsies: observer variation of semiquantitative and quantitative steatosis assessment. Virchows Arch, 461(2), 177-183 (2012).

56. Oliver JB, Peters S, Bongu A et al. Prerecovery liver biopsy in the brain-dead donor: a case-control study of logistics, safety, precision, and utility. Liver Transpl, 20(2), 237-244 (2014).

57. *El-Badry AM, Breitenstein S, Jochum W et al. Assessment of hepatic steatosis by expert pathologists: the end of a gold standard. Ann Surg, 250(5), 691-697 (2009).

58. *Spitzer AL, Lao OB, Dick AA et al. The biopsied donor liver: incorporating macrosteatosis into high-risk donor assessment. Liver Transpl, 16(7), 874-884 (2010).

59. Angele MK, Rentsch M, Hartl WH et al. Effect of graft steatosis on liver function and organ survival after liver transplantation. Am J Surg, 195(2), 214-220 (2008).

60. Briceno J, Ciria R, Pleguezuelo M et al. Impact of donor graft steatosis on overall outcome and viral recurrence after liver transplantation for hepatitis $\mathrm{C}$ virus cirrhosis. Liver Transpl, 15(1), 37-48 (2009).

61. Botha JF, Thompson E, Gilroy R et al. Mild donor liver steatosis has no impact on hepatitis $C$ virus fibrosis progression following liver transplantation. Liver Int, 27(6), 758-763 (2007).

62. Burra P, Loreno M, Russo FP et al. Donor livers with steatosis are safe to use in hepatitis C virus-positive recipients. Liver Transpl, 15(6), 619-628 (2009).

63. Baccarani U, Isola M, Adani GL et al. Steatosis of the hepatic graft as a risk factor for post-transplant biliary complications. Clin Transplant, 24(5), 631-635 (2010).

64. Lattanzi B, Lai Q, Guglielmo $\mathrm{N}$ et al. Graft macrosteatosis and time of T-tube removal as risk factors for biliary strictures after liver transplantation. Clin Transplant, 27(3), E332-338 (2013). 
65. Subramanian V, Seetharam AB, Vachharajani $\mathrm{N}$ et al. Donor graft steatosis influences immunity to hepatitis $C$ virus and allograft outcome after liver transplantation. Transplantation, 92(11), 1259-1268 (2011).

66. Adam R, Cailliez V, Majno P et al. Normalised intrinsic mortality risk in liver transplantation: European Liver Transplant Registry study. Lancet, 356(9230), 621-627 (2000).

67. Burroughs AK, Sabin CA, Rolles K et al. 3-month and 12-month mortality after first liver transplant in adults in Europe: predictive models for outcome. Lancet, 367(9506), 225-232 (2006).

68. European Liver Transplant Registry. Available at: http://www.eltr.org. Accessed September 2008.).

69. *Ballarin R, Cucchetti A, Spaggiari M et al. Long-term follow-up and outcome of liver transplantation from anti-hepatitis $C$ virus-positive donors: a European multicentric case-control study. Transplantation, 91(11), 1265-1272 (2011).

70 Berenguer M. Risk of extended criteria donors in hepatitis $C$ virus-positive recipients. Liver Transpl, 14 Suppl 2, S45-50 (2008).

71. Burr AT, Li Y, Tseng JF, Saidi RF, Bozorgzadeh A, Shah SA. Survival after liver transplantation using hepatitis $C$ virus-positive donor allografts: case-controlled analysis of the UNOS database. World J Surg, 35(7), 1590-1595 (2011).

72. *Northup PG, Argo CK, Nguyen DT et al. Liver allografts from hepatitis C positive donors can offer good outcomes in hepatitis C positive recipients: a US National Transplant Registry analysis. Transpl Int, 23(10), 1038-1044 (2010).

73. O'Leary JG, Neri MA, Trotter JF, Davis GL, Klintmalm GB. Utilization of hepatitis C antibody-positive livers: genotype dominance is virally determined. Transpl Int, 25(8), 825-829 (2012).

74. Cholongitas E, Papatheodoridis GV, Burroughs AK. Liver grafts from anti-hepatitis B core positive donors: a systematic review. J Hepatol, 52(2), 272-279 (2010).

75. Prieto M. Antibody to hepatitis B core antigen-positive grafts: not perfect but no longer marginal. Liver Transpl, 15(10), 1164-1168 (2009). 
76. Loggi E, Bihl F, Chisholm JV, 3rd et al. Anti-HBs re-seroconversion after liver transplantation in a patient with past HBV infection receiving a HBsAg positive graft. J Hepatol, 50(3), 625-630 (2009).

77. Yu L, Koepsell T, Manhart L, Ioannou G. Survival after orthotopic liver transplantation: the impact of antibody against hepatitis B core antigen in the donor. Liver Transpl, 15(10), 13431350 (2009).

78. *Angelico M, Nardi A, Marianelli T et al. Hepatitis B-core antibody positive donors in liver transplantation and their impact on graft survival: evidence from the Liver Match cohort study. J Hepatol, 58(4), 715-723 (2013).

79. MacConmara MP, Vachharajani N, Wellen JR et al. Utilization of hepatitis B core antibody-positive donor liver grafts. HPB (Oxford), 14(1), $42-48$ (2012).

80. Brock GN, Mostajabi F, Ferguson N et al. Prophylaxis against de novo hepatitis B for liver transplantation utilizing hep B core $(+)$ donors: does hepatitis $\mathrm{B}$ immunoglobulin provide a survival advantage? Transpl Int, 24(6), 570-581 (2011).

81. Skagen CL, Jou JH, Said A. Risk of de novo hepatitis in liver recipients from hepatitis-B core antibody-positive grafts - a systematic analysis. Clin Transplant, 25(3), E243-249 (2011).

82. Calne RY, Williams R. Liver transplantation in man. I. Observations on technique and organization in five cases. Br Med J, 4(5630), 535-540 (1968).

83. Broomhead RH, Patel S, Fernando B, O'Beirne J, Mallett S. Resource implications of expanding the use of donation after circulatory determination of death in liver transplantation. Liver Transpl, 18(7), 771-778 (2012).

84. Wells M, Croome KM, Janik T, Hernandez-Alejandro RM, Chandok NM. Comparing outcomes of donation after cardiac death versus donation after brain death in liver transplant recipients with hepatitis C: a systematic review and meta-analysis. Can J Gastroenterol Hepatol, 28(2), 103-108 (2014).

85 Nguyen JH, Bonatti H, Dickson RC et al. Long-term outcomes of donation after cardiac death liver allografts from a single center. Clin Transplant, 23(2), 168-173 (2009). 
86. Skaro AI, Jay CL, Baker TB et al. The impact of ischemic cholangiopathy in liver transplantation using donors after cardiac death: the untold story. Surgery, 146(4), 543-552; discussion 552-543 (2009).

87. Mathur AK, Heimbach J, Steffick DE, Sonnenday CJ, Goodrich NP, Merion RM. Donation after cardiac death liver transplantation: predictors of outcome. Am J Transplant, 10(11), 2512-2519 (2010).

88. Abou Abbass A, Abouljoud M, Yoshida A et al. Biliary complications after orthotopic liver transplantation from donors after cardiac death: broad spectrum of disease. Transplant Proc, 42(9), 3392-3398 (2010).

89. Bartlett A, Vara R, Muiesan P et al. A single center experience of donation after cardiac death liver transplantation in pediatric recipients. Pediatr Transplant, 14(3), 388-392 (2010).

90. Yagci G, Fernandez LA, Knechtle SJ et al. The impact of donor variables on the outcome of orthotopic liver transplantation for hepatitis C. Transplant Proc, 40(1), 219-223 (2008).

91. Tao R, Ruppert K, Cruz RJ, Jr. et al. Hepatitis C recurrence is not adversely affected by the use of donation after cardiac death liver allografts. Liver Transpl, 16(11), 1288-1295 (2010).

92. Mawardi M, Aba Alkhail F, Katada K et al. The clinical consequences of utilizing donation after cardiac death liver grafts into hepatitis C recipients. Hepatol Int, 5(3), 830-833 (2011).

93. Hernandez-Alejandro R, Croome KP, Quan D et al. Increased risk of severe recurrence of hepatitis $C$ virus in liver transplant recipients of donation after cardiac death allografts. Transplantation, 92(6), 686-689 (2011).

94. Taner CB, Bulatao IG, Keaveny AP et al. Use of liver grafts from donation after cardiac death donors for recipients with hepatitis C virus. Liver Transpl, 17(6), 641-649 (2011).

95. Uemura T, Ramprasad V, Hollenbeak CS, Bezinover D, Kadry Z. Liver transplantation for hepatitis $\mathrm{C}$ from donation after cardiac death donors: an analysis of OPTN/UNOS data. Am J Transplant, 12(4), 984-991 (2012).

96. Tariciotti L, Rocha C, Perera MT et al. Is it time to extend liver acceptance criteria for controlled donors after cardiac death? Transplantation, 92(10), 1140-1146 (2011). 
97. Monbaliu D, Pirenne J, Talbot D. Liver transplantation using Donation after Cardiac Death donors. J Hepatol, 56(2), 474-485 (2012).

98. **Fondevila C, Hessheimer AJ, Flores E et al. Applicability and results of Maastricht type 2 donation after cardiac death liver transplantation. Am J Transplant, 12(1), 162-170 (2012).

This is the largest series of type 2 DCD liver transplants published to date.

99. Harring TR, Nguyen NT, Cotton RT et al. Liver transplantation with donation after cardiac death donors: a comprehensive update. J Surg Res, 178(1), 502-511 (2012).

100. Jay CL, Skaro AI, Ladner DP et al. Comparative effectiveness of donation after cardiac death versus donation after brain death liver transplantation: Recognizing who can behefit. Liver Transpl, 18(6), 630-640 (2012).

101. **McCormack L, Petrowsky H, Jochum W, Mullhaupt B, Weber M, Clavien PA. Use of severely steatotic grafts in liver transplantation: a matched case-control study. Ann Surg, 246(6), 940-946; discussion 946-948 (2007).

This matched case-control study compared LTs after the use of normal or severe steatotic livers 102. **Dutkowski P, Schlegel A, Slankamenac K et al. The use of fatty liver grafts in modern allocation systems: risk assessment by the balance of risk (BAR) score. Ann Surg, 256(5), 861868; discussion 868-869 (2012).

Authors combined the 2largest available databases (UNOS and ELTR) in one comprehensive model, to analyze outcome in biopsy-proven liver graft steatosis according to risk strata defined by the BAR (balance of risk) scoring system (published before from the same team)

103. Scalea JR, Barth RN, Munivenkatappa R,et al. Shorter waitlist times and improved graft survivals are observed in patients who accept hepatitis $C$ virus + renal allografts. Transplantation, 99(6),:1192-6 (2015).

104. Aubert O, Kamar N, Vernerey D, et al. Long term outcomes of transplantation using kidneys from expanded criteria donors: prospective, population based cohort study. BMJ, 2015 Jul 31;351:h3557. doi: 10.1136/bmj.h3557. 
Table 1. Milestones in the definiton of ECD

\begin{tabular}{|c|c|c|c|c|c|c|c|}
\hline & Barshes (2007) [2] & $\begin{array}{c}\text { Nickkholgh. (2007) } \\
\text { [3] }\end{array}$ & Northup. (2007) [4] & $\begin{array}{c}\text { Burroughs (2009) } \\
{[16]}\end{array}$ & Blok (2012) [20] & Bruzzone (2013) [21] & Feng S (2014) [8] \\
\hline Donor ICU & & $\begin{array}{l}\text { ICU stay and } \\
\text { ventilation support }>7 \\
\text { days, }\end{array}$ & on vasopressors & $\begin{array}{l}\text { hospital stay }>5 \\
\text { days, }\end{array}$ & ay $>7$ days; & $\begin{array}{l}\text { ICU stay with } \\
\text { ventilation }>7 \text { days }\end{array}$ & \\
\hline BMI & & $>30$ & $>30$ & & high & $\mathrm{BMI}>30$ & height /weight \\
\hline $\begin{array}{l}\text { Donor cause } \\
\text { of death }\end{array}$ & $\begin{array}{l}\text { anoxia, CVA or other non- } \\
\text { trauma cause) }\end{array}$ & & anoxia, CVA & & & & anoxia, CVA \\
\hline $\begin{array}{l}\text { Donor race } \\
\text { and age }\end{array}$ & black donor $\geq 60$ years of age & donor age $>65$ yrs & black donor of any age & & $\begin{array}{l}\text { donor age }>65 \\
\text { yrs }\end{array}$ & age up to $80 \mathrm{yrs}$ & $\begin{array}{l}\text { black race, and } \\
\text { age }>60\end{array}$ \\
\hline Steatosis & & $\begin{array}{l}\text { biopsy proven } \\
\text { steatosis }>40 \%,\end{array}$ & steatosis $>40 \%$ & & $\begin{array}{l}\text { steatosis (not } \\
\text { specified) }\end{array}$ & steatosis & \\
\hline serum $\mathrm{Na}+$ & & $\begin{array}{l}\text { peak serum } \mathrm{Na}+>165 \\
\mathrm{mmol} / \mathrm{l} \text {, }\end{array}$ & elevated serum $\mathrm{Na}$ & & $\begin{array}{l}\text { hyperNa (not } \\
\text { specified) }\end{array}$ & $\begin{array}{l}\text { serum } \mathrm{Na}>165 \\
\mathrm{mmol} / \mathrm{L}\end{array}$ & \\
\hline $\begin{array}{l}\text { Liver } \\
\text { function tests }\end{array}$ & & $\begin{array}{l}\text { ALAT / ASAT }>3 x \\
\text { normal, serum } \\
\text { bilirubin }>3 \mathrm{mg} / \mathrm{dL} \text {, }\end{array}$ & $\begin{array}{l}\text { elevated serum } \\
\text { bilirubin }\end{array}$ & & $\begin{array}{l}\text { elevated } \\
\text { ASAT/ALAT and } \\
\text { se. bilirubine (not } \\
\text { specidfed) }\end{array}$ & $\begin{array}{l}\text { ASAT }>90 \mathrm{U} / \mathrm{L}, \text { ALAT } \\
>105 \mathrm{U} / \mathrm{L} \\
\text { serum bilirubin }>3 \\
\mathrm{mg} / \mathrm{dL}\end{array}$ & \\
\hline $\begin{array}{l}\mathrm{HCV} / \mathrm{HBV} \\
\text { serology }\end{array}$ & & $\begin{array}{l}\text { positive serology for } \\
\text { viral hepatitis }\end{array}$ & & & & & \\
\hline Graft type & $\begin{array}{l}\text { split liver/ partial liver from a } \\
\text { donor that is } \geq 40 \text { years of age; } \\
\text { or }<40 \text { years of age and black; }\end{array}$ & & & & & & all split liver grafts \\
\hline DCD & $\begin{array}{l}\text { donation after cardiac death } \\
\text { (DCD) together with any of the } \\
\text { following: ( } \geq 40 \text { years of age; } \\
<40 \text { years of age and black; or } \\
<40 \text { years of age and whose } \\
\text { COD was either anoxia, CVA } \\
\text { or other non-trauma cause }\end{array}$ & & & & & & any DCD \\
\hline Allocation & CIT $>12$ hours & & & $\begin{array}{l}\text { CIT }>12 \mathrm{~h} \text {, and } \\
\text { WIT }>40 \mathrm{~min}\end{array}$ & & & $\begin{array}{l}\text { Regional/ national; } \\
\text { and CIT }\end{array}$ \\
\hline $\begin{array}{l}\text { Other donor } \\
\text { factors }\end{array}$ & & $\begin{array}{l}\text { sepsis, meningitis, } \\
\text { history of extrahepatic } \\
\text { malignancy, previous } \\
\text { drug abuse. }\end{array}$ & $\begin{array}{l}6 \text { months history of } \\
\text { alcohol and/or } \\
\text { cocaine dependency, } \\
\text { malignancy, diabetes } \\
\text { mellitus }\end{array}$ & & & & \\
\hline
\end{tabular}


